clinical nursing education: a scoping review. Nurs Educ Perspect. 2019 Jul/Aug; 40(4):205-9. Doi: 10.1097/01.NEP.0000000000000469.

59. Singh S, Cotts KG, Maroof KA, Dhaliwal U, Singh N, Xie T. Disabilityinclusive compassionate care: Disability competencies for an Indian Medical Graduate. J Family Med Prim Care. 2020;9(3):1719-27.

60. Drexel University website. Accommodations, Disability Resources from the Office of Equality and Diversity; Philadelphia, PA. Date unknown[cited 2020 May 29] Available from https://drexel.edu/oed/ disabilityResources/students/Accommodations/

61. Indian Nursing Council. Resolutions F.No.1-5/2014. New Delhi: INC; 2014[cited 2020 Sep 5]. Available from http://nmcouncil.ap.nic.in/ circular/1.pdf

62. Leenie Quinn, Adaptive athlete, nurse and rugger, born with one hand Headsntales Blog. 2015 Nov 8 [cited 2020 Sep]. Available from: http:// www.headsntales.org/blog/10
63. Neal-Boylan L. Having a disability may make you a better nurse. Workplace Health Saf. 2019 Nov; 67(11):567-8. doi: 10.1177/2165079919860541.

64. York University website. Information for Applicants with Diagnosed Disabilities. Date unknown [cited 2020 May 30]. Available from https://futurestudents.yorku.ca/requirements/applicants-diagnoseddisabilities

65. Matt SB, Maheady D, Fleming SE. Educating nursing students with disabilities: Replacing essential functions with technical standards for program entry criteria.Journal on Postsecondary Education and Disability. 2015; 28 (4):461-8. Available from https://eric.ed.gov/?id=EJ1093588

66. Howlin F, Halligan P, O'Toole S. Development and implementation of a clinical needs assessment to support nursing and midwifery students with a disability in clinical practice: part 1. Nurse Educ Pract. 2014 Sep;14(5):557-64. doi: 10.1016/j.nepr.2014.07.003.

\title{
Non-invasive prenatal testing: Special interest groups vs women's autonomy
}

\section{LARS H BREIMER}

\begin{abstract}
Non-invasive prenatal testing (NIPT) is moving the goalposts for the detection of genetic disorders such as Down Syndrome (DS). NIPT not only misses fewer cases than first trimester combined screening, but also has fewer false positive results. Unlike with neural tube defect (NTD) where screening to detect affected pregnancies was welcomed, NIPT for trisomy has met with surprising resistance. This paper argues that special interest groups have been allowed to usurp influence beyond what is balanced in the discussions, at the expense of the fight against sex selection. The fear of parents of children with DS, that their children's rights might be devalued, must not trump the autonomy of pregnant women to decide what is best for their own family and what they can cope with emotionally and financially. Society, however, must ensure that resources for caring for those with DS and other disabilities remain adequate. Here, recent articles are also reviewed.
\end{abstract}

Keywords: NIPT, prenatal testing, Down Syndrome, trisomy, autonomy of pregnant women, children's rights

\section{Introduction}

Everyone wants their child to be healthy, and the vast majority of children are in fact born healthy. To ensure this, carrier-

Author: Lars H Breimer (lars.breimer@regionorebrolan.se), School of Health and Medical Sciences, Örebro University, Department of Laboratory Medicine, Clinical Chemistry Division,Örebro University Hospital, SE-701 85 Örebro, SWEDEN.

To cite: Breimer LH. Non-invasive prenatal testing: Special interest groups vs women's autonomy. Indian J Med Ethics. 2020 Oct-Dec; 5(4)NS: 285-90. DOI:10.20529/JME.2020.069.

Published online on June 20, 2020.

Manuscript Editor: Nikhil Govind

Peer Reviewers: Two anonymous peer reviewers

(c) Indian Journal of Medical Ethics 2020 screening and prenatal diagnosis have long been established and the foetal milestones well recognised. In the 1960s, amniocentesis with karyotyping came into practice and later testing for neural tube defect (spina bifida) with alphafetoprotein, which was subsequently developed for maternal blood. In 1971, carrier-identification for Tay-Sachs disease was introduced, and about six years later, screening for thalassemiacarriers around the Mediterranean. Today, genetic testing has replaced the blood test. Second trimester screening was succeeded by first trimester combined screening (FTC) with ultrasound and biochemical markers about 20 years ago. Noninvasive prenatal testing (NIPT) started on a large scale about five years ago. It can detect trisomy 21, 18 and 13 - Down syndrome (DS), Patau syndrome and Edwards syndrome, respectively - with high accuracy.

I became interested in how NIPT was viewed in the community last autumn, after I attended a meeting discussing prenatal diagnosis and discovered that the majority of the participants were against pre-natal diagnosis and that $50 \%$ of them had a child with a serious condition, mostly DS, that could have been diagnosed during pregnancy. When I told other colleagues, I learnt that their experiences had been similar. Unfortunately, there are no published summaries from those meetings so they cannot be referenced.

When DS is detected by genetic screening during pregnancy, the vast majority of prospective parents choose to terminate the pregnancy. One study in China found that all (99/99) the women studied terminated their pregnancy when the foetus was detected with trisomy 21,18 or 13 ; while only 25 $\%(6 / 24)$ terminated for sex chromosome anomalies (1). As many European countries do not require a medical reason for termination of a pregnancy, it is not possible to study the rates. Nevertheless, it has repeatedly been claimed in media reports, that the abortion rate for DS is $90 \%$ or higher in many European countries; and the data from Denmark does show a fall in births with DS - from 100 -120 per 100,000 live births 
before the year 2000, to 24 per 100,000 in 2018 in spite of increasing maternal age $(2,3)$. A study from the US (4) before NIPT became generally available found that termination rates for DS were $86-90 \%$ in hospitals and $72-93 \%$ in populationbased studies, and also that the rate was $100 \%$ in four northern US states, and $<50 \%$ in southern USA (in some states zero), possibly reflecting ease of access to terminations.

Media campaigns two years apart claimed that Iceland was forcing abortion of all its DS foetuses. These reports were refuted by the Icelandic government explaining the facts (5). Likewise, Denmark and Sweden have been subjected to aggressive attacks from the anti-abortion lobby through the media. Because of the high abortion rate, some groups argue that prenatal testing for DS is discriminatory towards people with this condition. It is fitting, as the Swedish State Medical Ethical Council and the Swedish State Committee for Medical and Social Evaluation (SBU) argue in several reviews that society should provide good support for families and individuals with DS. SBU's review of NIPT in 2015 (6) states -"From an ethical point of view it is extremely important that there is good social support for people with disabilities", but it then goes on to claim that "there is a potential risk that offering prenatal diagnostics of T13, 18 and 21 may be seen as devaluing and inducing discrimination of individuals with these trisomies" - without explaining on what ethical grounds they would require pregnant women to continue with their pregnancies. DS interest groups, like several other interest groups, have a tendency not to declare a conflict of interest when commenting on prenatal diagnosis and its implications, which is a pernicious practice (7).

The DS interest groups argue that if a nation transfers costs to families and individuals then prenatal diagnosis must stop. One could argue that a constructive view would be that if fewer children are born with DS, it would be easier for society to adequately ensure secure funding for those affected by the condition. In many countries around the world, there is very little support from the public purse for these children, so the cost is born by the family. Here I review 12 recent studies that directly or indirectly address attitudes of pregnant couples to NIPT $(8-17,21)$, only two of which $(8,14)$ are theoretical discussions.

\section{Recent studies on women's perspectives on the ethical implications of NIPT}

\section{The Canadian Delphi study}

A Delphi study from Canada was published in 2019 (8). The Delphi method is a forecasting process using multiple rounds of questionnaires sent to a panel of experts, whose anonymous responses are aggregated and shared with the group after each round. Briefly, issues relating to prenatal diagnosis were discussed in three rounds with 61, 58 and 49 persons in each group. The paper presented details about the people involved. One group comprised "patients or disability rights advocates", of which there were 17, 16 and 14 individuals in each round, among whom, 4, 4 and 4 had an "association specific to Down syndrome" were 4, 4 and 4 participants in each round. In addition, there were 10,9, and 6 representatives of various religions. Among "potentially influencing factors", 23 $\%$ had a child with a disability, while with some overlap, $86 \%$ knew one; $45 \%$ had experienced prenatal screening, and $17 \%$ had undergone prenatal diagnosis, though the study did not identify whether NIPT or FTC. Thus, though in some aspects the study members were representative of Canadians in general, in other aspects they were not, though the article neither comments on this nor on any risk of bias.

\section{Studies considering costs to families and third parties}

Three recently published papers, one each from South Korea, Mexico and the US, address not only the incidence of children born with DS, but also the significant costs that affect their families $(9-11)$. Briefly, these studies can be summarised as follows:

- The Korean study by Park et al (9) compared the number of children born with DS between 2007 and 2016 and found that, despite the increase in the average age of the mothers (a major risk factor for DS), the number of DS births was constant at about 5 per 10,000 live births. The differences between observed and model-based frequency of expected rate of DS births was more than 10 per 10,000 born in 2007; and 15 per 10,000 born in 2015, indicating that pregnant women were terminating their pregnancy when they perceived a high risk of DS.

The study also found that the medical expenses for children with DS were about ten times higher than for nonDS children, and the direct costs to the families were about twice as high (9). Based on this, the authors recommended that "public policies should be implemented to provide adequate antenatal care for mothers and to prevent economic burden of medical care for infants and children with DS".

- The Mexican study (10), while stating that the number of births with DS had dropped significantly (from 11.5-15.5 in 2007 to $3.7-4.6$ per 10,000 a year later), focused primarily on the heavy burden of supporting a child with DS in Mexico, where costs are not covered by the general health and social services after the child reaches the age of five. It was estimated that the annual expenditure for a child with DS accounted for $27 \%$ of the available household income. On average, $33 \%$ of families with DS children had disastrous expenses, and $46 \%$ of families had to borrow money to pay for medical expenses (10).

- A 2017 north-American study (11) conducted between 1999 and 2013 in Boston and Montreal found that, overall, patients with DS incurred incremental medical costs directly to the family of $\$ 18,248$ (per child with DS) between birth and 18 years, while third-party payers (health insurance companies, etc) paid incremental costs of $\$ 230,043$ per child with DS during the same period.

According to all three studies, the extra costs for a child with DS are very substantial and hit families hard in countries such as 
Mexico and South Korea. In countries with tax-financed health care systems that are increasingly underfinanced, sooner or later an increasing proportion of the costs will be passed on to the families. In this situation, a positive foetal diagnostic test will become a financial reality for the family.

\section{Some other recent papers worth considering in this context}

The first interim report on the ongoing Dutch Trident-2 study (April 1, 2017 to April 2023), has just been published (12). In the Netherlands, the cost of foetal diagnosis is not covered, but those who entered the study received NIPT at the same price as FTC ie 175 Euros. In the first year, $42 \%$ of all pregnant women chose NIPTs $(73,239)$ while $4 \%$ chose KUB, and $52 \%$ did not participate. However, it was estimated that $3-5 \%$ underwent NIPT privately outside of Trident-2. (In Belgium, the personal cost for the NIPT laboratory test is Euros 263.25 when not covered by the Belgian insurance, but private providers in European countries often charge considerably more for their service, 500-700 Euros.) This shows preference for NIPT even when paying.

Almost $80 \%$ of those who opted for NIPT chose to be informed of more findings than trisomy 21, 18 and 13. This was unexpectedly high. The positive predictive values were also unexpectedly high - $96 \%$ for trisomy $21,98 \%$ for trisomy 18 and $53 \%$ for trisomy 13 . The authors considered the fact that less than $50 \%$ of pregnant women undertook prenatal diagnostics could be due to several factors such as cost, a negative attitude towards abortion, and a positive attitude towards DS, and that the offer for testing focused on the right not to need to know. The article also covered the unusual trisomies and other chromosomal anomalies.

A second Dutch article is from a group of medical ethicists, philosophers and clinical geneticists at Erasmus University in Rotterdam (13). The article is an ethical discussion about whether it was justified to charge pregnant women (in whole or part) for NIPT. Two issues were discussed: whether payment would slow down the adoption of NIPT; and whether payment would ensure that pregnant women made an informed choice.

The authors considered that the use of financial instruments to curb the use of a screening system violated the basic principle of screening, that as many as possible should benefit (13). They also considered that payment disproportionately affects the lower socio-economic groups, blocking their access to prenatal diagnosis. The authors also felt that there was no evidence linking payment to better informed choices. The authors advised that to promote informed decisions, the healthcare system should instead invest in adequate counselling before prenatal diagnosis, and at the time the results were communicated.

\section{Women's personal experiences of NIPT}

Some researchers have also looked at how pregnant women experienced pre-natal diagnosis with NIPT:

- A German review paper examined in detail five studies with validated instruments which had assessed anxiety, psychological distress and/or regret over decisions among women (14), while two studies had interviewed women or held focus group discussions. It was found that the women's anxiety decreased when the test results showed a low risk of trisomy. They also found that few women regretted their decision - whether it was to terminate their pregnancy or continue. However, there was no longterm follow-up of the attitudes of the partners of the pregnant women.

- The preferences of Canadian women, their partners and health-professionals regarding NIPT use and access has also been studied by the group that did the Delphi study cited above (15). They looked at 882 pregnant women, 395 partners and 184 healthcare professionals. When the women and their partners were asked if they were concerned that NIPT being covered as part of routine prenatal care could lead to increased pressure, the majority of women reported "no concern" whatsoever and only $1.8 \%$ reported being "very concerned". This suggests that the impact of public funding for NIPT would enhance autonomy in women's decision-making. Almost 4 out of 5 pregnant women preferred NIPT to FTC for first-tier screening due to its greater accuracy and speed. More than $2 / 3$ of the women preferred NIPT to amniocentesis as a diagnostic test in spite of the minimal possibility of false positives /negatives. Several were willing to pay up to 499 Canadian dollars for NIPT, except in Ontario where NIPT is provided free for high-risk pregnancies (15).

- Vanstone et al looked at the perspectives of 38 women who had undergone NIPT on the ethical implications of the test by using an adapted version of constructive grounded theory (16). They found that overall, the participants were dissatisfied with NIPT being offered only to women at high risk and with its high cost. All participants in the study supported access to NIPT for all women as the initial prenatal test and felt restricting use went against Canada's commitment to universal care. They felt it was entirely the woman's right to choose how to use the information about the health status of the foetus. At the same time, the women feared that NIPT would be used for sex selection. They were also critical of terminations for "frivolous" reasons. The earlier availability of the results (compared with FTC) was seen as positive because it avoided the physical and emotional difficulties of later terminations. Several of the women also considered that governments should consider potential savings in long-term healthcare costs and social support when affected pregnancies were terminated. Whatever the system paid for testing, the system would save down the line in the cost of care for disabled children and their hospital costs including intensive care, even if they only lived for a few weeks or months after birth.

- A comparative study conducted in Quebec, Canada, and Beirut, Lebanon, found that the biggest fear the women participants had regarding NIPT was its possible use for sex-selection (17). In Lebanon abortion is essentially 
illegal, though it occurs clandestinely; while in Quebec it is much more freely available. Yet in both, the common fear expressed by the women interviewed was, that with NIPT, female foetuses would be aborted. That NIPT is used for sex-selection is supported by the extensive smuggling of blood-samples from mainland China, where sexdetermining and reporting is forbidden, to Hong Kong were it is allowed, reported at least as early as 2017 (18), and again in 2019 (19). Oddly enough, a discussion paper in 2019 did not consider sex-selection a significant issue with NIPT (20).

- A British team conducted a mixed methods study to assess women's experience of being offered NIPT using validated measures of decisional conflict, decisional regret, and anxiety (21). A cross-sectional survey and semi-structured interviews were conducted at the time of testing and one month following receipt of results (or equivalent for NIPT decliners). In total, 845 questionnaires and 81 interviews were analysed. Decisional conflict occurred in $3.8 \%$ of the cases, but none of the participants experienced decisional regret.

- A similar study was performed in the Netherlands of 682 pregnant women with elevated risk for foetal aneuploidy based on first-trimester combined test (risk $\geq 1: 200$ ) or medical history, who were offered NIPT in the nationwide Dutch TRIDENT study (22). Pre- and post-test questionnaires included measures on: experiences with NIPT procedure, feelings of reassurance, anxiety, child-related anxiety, and satisfaction. The majority (96\%) were glad to have been offered NIPT. Most women with a normal NIPT result felt reassured $(81 \%)$ or somewhat reassured (16\%). Levels of anxiety and child-related anxiety were significantly lower after receiving a normal NIPT result $(p<0.001)$.

- A study in Australia came to essentially similar conclusions, that NIPT was well received and women were reassured by a result indicating low risk (23).

These studies have shown that when a pregnant woman receives a message that her foetus does not have trisomy, she experiences the prenatal diagnoses process as positive (14-16, 21-23). This is not surprising; it reflects human nature. In contrast, when the message is that of a trisomy, the women report substantial dissatisfaction with the process, complaining about a number of features. This too is not surprising. They are forced to make a decision. It is also reassuring that there is no regret about the decision taken.

\section{General observations and possible future directions}

Where it has been studied, sex-selection is the single biggest concern among women about NIPT. Surprisingly, this critical point is not reported on nor discussed in most of the studies on attitudes to NIPT. Why this is so, is far from clear. It could be that the researchers consider it self-evident (ie not worth spending effort on), or even see it as a distraction, or simply that in many countries, including the USA, it is not forbidden to reveal the sex of the foetus. Education alone will not be enough here; legislation is required.
It is too early to tell what the role of NIPT will be. Today we have a situation where one country, Belgium, moved the goalposts in 2017 when it introduced NIPT as the primary screening system at a nominal fee (8, 68 Euros, ca 9 USD). Belgium is $50 \%$ Catholic and $33 \%$ non-religious (24). The Netherlands has chosen to undertake a substantial study as part of an ordered introduction $(12,22)$. As the Canadian structured interview study (16) found, women not only expect NIPT to be available to all but they also consider it their own right to decide about how to proceed with a foetus with a disability. In all countries without subsidised or free NIPT, it is available privately and paid for out of pocket. The cost varies but is usually considerably higher than the lowest prices charged by reputable labs as judged by surveying the Internet. Nevertheless, in comparison to the lifelong cost of raising a severely disabled child, it is a trivial amount, as illustrated by the South Korean, Mexican, and American studies (9-11). This author can't help but reflect that if NIPT was a test for prostate cancer, it would have swept PSA from the stage long ago. It seems bizarre to discuss the cost-effectiveness of various forms of screening, divorced from the costs incurred for a severely disabled child to the family and society, yet many (if not all) discussions about the cost-effectiveness of prenatal screening do not make the comparison.

Hopefully, in the near future we shall see more analyses of costs of subsidised universal screening compared to screening at market rates paid out of pocket, cost of long term care of an affected person, and the profits earned by private providers. Such analyses might explain why there is so little pressure from the profession to introduce universal screening from the public purse, including the overall cost of long-term care.

It would be interesting to see further analyses of how religious beliefs may impact women's choices on whether to screen or not, in the context of national religion, culture, equality and human development.

The heated debate around better screening for trisomy should be compared to the case of neural tube defect (NTD or spina bifida). In NTD, methods for prenatal screening were welcomed. Screening with alpha-fetoprotein (AFP) first in amniotic fluid, and then in maternal blood, was introduced several years before Laurence's and Smithells' groups (25-31) showed that supplementation of diet with folate could prevent neural tube defects. Ultrasound screening has now replaced AFP, and today very few babies are born with NTD in developed countries, although the condition is still a major health problem in many poorer countries. What is controversial today is that the socalled Groeningen Protocol allows for new-borns with NTD to be euthanised (32). The principle of screening and termination in NTD is seen as self-evident.

\section{Conclusion}

Smithells, Laurence and Lorber had earlier demonstrated the huge negative economic, social and psychological impact NTD had on families, including high divorce rates and the damage to the oldest daughter who had to act as a second 
mother, as reviewed by Breimer and Nilsson (31). Developing nations do not have the resources of rich countries, but the use of cheap ultrasound to identify and selectively abort female foetuses shows how dangerous unregulated screening can be. Sex-selection by NIPT is even simpler. It also illustrates how powerful the market place is even when the outcome is a disaster for society. That this occurs not only in nations such as China and India but also in rich countries like the USA (33) and Western Europe, at least among immigrants to those nations from areas where girls are not highly valued, illustrates the problems in society. Nevertheless, it is hard to see how screening to exclude births with untreatable congenital handicaps should not be seen as an improvement. At the same time, every effort to prevent sex-selected foeticide must be supported.

Conflict of interest and funding: The author reports no conflicts of interest and no funding for this work.

\section{References}

1. Zhou Q, Zhu ZP, Zhang B, Yu B, Cai ZM, Yuan P. Clinical features and pregnancy outcomes of women with abnormal cell-free fetal DNA test results. Ann Transl Med. 2019 Jul;7(14):317. doi: 10.21037/ atm.2019.06.57.

2. Forte DF. From termination to extermination: The international Down syndrome genocide. Public Discourse. 2018 Jul 23 [cited 2020 May 12]. Available from: https://www.thepublicdiscourse.com/2018/07/21996/

3. Will GF. The real Down syndrome problem: accepting genocide Washington Post. 2018 Mar 15 [cited 2020 May14]. Available from: https://www.washingtonpost.com/opinions/whats-the-real-downsyndrome-problem-the-genocide/2018/03/14/3c4f8ab8-26ee-11e8b79d-f3d931db7f68_story.html

4. Natoli JL, Ackerman DL, McDermott S, Edwards JG. Prenatal diagnosis of Down syndrome: a systematic review of termination rates (1995-2011). Prenatal Diagn. 2012 Feb; 32(2):142-53.

5. Embassy of Iceland in London. Facts about Down's syndrome and prenatal screening in Iceland. 2018 Mar 26 [cited 2020 May 12]. Available from: https://www.government.is/diplomatic-missions/embassyarticle/2018/03/26/Facts-about-Downs-syndrome-and-pre-natalscreening-in-Iceland/

6. SBU Alert Rapport. Analys av foster-DNA i kvinnans blod: icke-invasiv fosterdiagnostik (NIPT) för trisomi 13,18 och 21 [Analysis of fetal DNA in women's blood: non-invasive fetal diagnosis (NIPT) for trisomy 13,18 and 21]. Stockholm:SBU; 2015 [cited 2020 May 12]; 68 pages. Available from: https://www.sbu.se/201503

7. Breimer LH, Nilsson TK, Breimer ME. Declarations of conflict of interest are still inadequate. Indian J Med Ethics. 2018 Jul-Sep [cited 2020 May 12];3(3):256-7. Available from: https://ijme.in/articles/ethicalstumbling-blocks-in-uncovering-folate-deficiency-as-a-preventablecause-of-spina-bifida/?galley=html

8. Dupras C, Birko S, Affdal A, Haidar H, Lemoine ME, Ravitsky V. Benefits, challenges and ethical principles associated with implementing noninvasive prenatal testing: a Delphi study. CMAJ Open. 2018 Oct 31; 6(4):E513-19. DOI:10.9778/cmajo.20180083.

9. Park GW, Kim NE, Choi EK, Yang HJ, Won S, Lee YJ. Estimating nationwide prevalence of live births with Down syndrome and their medical expenditures in Korea. J Korean Med Sci 2019 aug 12[cited2020 May 12]; 34(31):e207. Available from: https://www.ncbi.nlm.nih.gov/pmc/ articles/PMC6689486/

10. Martínez-Valverde S, Salinas-Escudero G, García-Delgado C, GarduñoEspinosa J, Morán-Barroso VF, Granados-García V, et al. Out-of-pocket expenditures and care time for children with Down syndrome: $A$ single-hospital study in Mexico City. PLoS ONE. 2019 Jan 10 [cited 2020 May 12]; 14(1): e0208076. Available from: https://doi.org/10.1371/ journal.pone.0208076

11. Kageleiry A, Samuelson D, Duh MS, Lefebvre P, Campbell J, Skotko BG. Out-of-pocket medical costs and third-party healthcare costs for children with Down syndrome. Am JMed Genet A. 2017 Mar; 173(3):62737.

12. van der Meij KRM, Sistermans EA, Macville MVE, Stevens SJC, Bax CJ, Bekker MN, et al for the Dutch NIPT Consortium. TRIDENT-2: national implementation of genome-wide non-invasive prenatal testing as a first-tier screening test in the Netherlands. Am J Hum Genet. 2019; 105: 1-11.

13. Bunnik EM, Kater-Kuipers A, Galjaard RH, de Beaufort ID. Should pregnant women be charged for non-invasive prenatal testing? Implications for reproductive autonomy and equal access. J Med Ethics. 2020 Mar; 46(3):194-8. doi: 10.1136/medethics-2019-105675.2019.

14. Labonté V, Alsaid D, Lang B, Meerpohl JJ. Psychological and social consequences of non-invasive prenatal testing (NIPT): a scoping review. BMC Pregnancy Childbirth. 2019 Oct 28; 19(1):385-98. doi: 10.1186/s12884-019-2518-x.

15. Birko S, Ravitsky V, Dupras C, Le Clerc-Blain J, Lemoine ME, Affdal AO, Haidar $\mathrm{H}$, Laberge AM. The value of non-invasive prenatal testing: preferences of Canadian pregnant women, their partners, and health professionals regarding NIPT use and access. BMC Pregnancy Childbirth. 2019 Jan 10;19(1):22-32.

16. Vanstone M, Cernat A, Nisker J, Schwartz L. Women's perspectives on the ethical implications of non-invasive prenatal testing: a qualitative analysis to inform health policy decisions. BMC Med Ethics. $2018 \mathrm{Apr}$ 16;19(1):27-39.

17. Haidar H,Vanstone M, Laberge A-M, Bibeau G, Ghulmiyyah L, Ravitsky V. Cross-cultural perspectives on decision making regarding noninvasive prenatal testing: A comparative study of Lebanon and Quebec. AJOB Empirical Bioethics. 2018; 9(2):99-111.

18. Hu T. Woman caught trying to smuggle 203 blood samples for baby gender tests into Hong Kong. South China Morning Post. 2017 Jul 28 [cited 2020 Jun 12]: Available from : https://www.scmp.com/news/ china/society/article/2104458/woman-caught-trying-smuggle-203blood-samples-baby-gender-tests

19. Zaugg J. Blood smuggling in China:Why pregnant women are breaking the law to find out their babies' sex. CNN. 2019 Oct 17 [cited 2020 Jun 12]. Available from: https://edition.cnn.com/2019/10/13/asia/hongkong-blood-smuggling-nipt-intl-hnk/index.html

20. Bowman-Smart H, Savulescu J, Gyngell C, Mand C, Delatycki MB. Sex selection and non-invasive prenatal testing: A review of current practices, evidence, and ethical issues. Prenatal Diagn. 2020 Mar; 40(4):398-407. Doi: 10.1002/pd.5555. Epub 2019 Oct 10.

21. Lewis C, Hill M, Chitty LS. Women's experiences and preferences for service delivery of non-invasive prenatal testing for aneuploidy in a public health setting: a mixed methods study. PLoS One. 2016 Apr 5; 11(4): e0153147.

22. van Schendel RV, Page-Christiaens GCML, Beulen L, Bilardo CM, de Boer MA, Coumans ABC, et al.; Dutch NIPT Consortium. Women's experience with non-invasive prenatal testing and emotional well-being and satisfaction after test-results.J Genet Couns. 2017 Jun 30;26(6): 1348-56.

23. Bowman-Smart $\mathrm{H}$, et al.'Small cost to pay for peace of mind': Women's experiences with non-invasive prenatal testing. Aust N Z J Obstet Gynaecol. 2019 Oct; 59(5): 649-55.

24. Central Intelligence Agency, USA. The World Factbook. Europe:Belgium. Updated 2020 Jun 10[cited 2020 Jun 12]. Available from: https://www. cia.gov/library/publications/resources/the-world-factbook/geos/ be.html

25. Milunsky A, Alpert E. The value of alpha-fetoprotein in the prenatal diagnosis of neural tube defects.J Pediatr. 1974 Jun; 84(6):889-93.

26. Alpert E. Alpha 1-fetoprotein: need for quantitative assays. N Engl J Med. 1974 Mar 7; 290(10):568-9.

27. Leighton PC, Kitau MJ, Chard T, Gordon YB, Leek AE. Levels of alphafetoprotein in maternal blood as a screening test for fetal neural-tube defect. Lancet. 1975 Nov 22;306(7943):1012-5.

28. Wald NJ, Cuckle H, Brock JH, Peto R, Polani PE, Woodford FP. Maternal serum-alpha-fetoprotein measurement in antenatal screening for anencephaly and spina bifida in early pregnancy. Report of UK collaborative study on alpha-fetoprotein in relation to neural-tube defects. Lancet. 1977 Jun 25;309(8026):1323-32.

29. Laurence KM, James N, Miller MH, Tenant GB, Campbell H. Double-blind randomized controlled trial of folate treatment before conception to prevent recurrence of neural-tube defects. Br Med J (Clin Res Ed). 1981 
May 9;282(6275):1509-11.

30. Smithells R W, Sheppard S, Schorah C J, Seller MJ, Nevin NC, Harris R, et al. Possible prevention of neural tube defects by peri-conceptional vitamin supplementation. The Lancet 1980 Feb 16;315(8164):339-40.

31. Breimer LH, Nilsson TK. Ethical stumbling blocks in uncovering folate deficiency as a preventable cause of spina bifida. Indian J Med Ethics.
2017 Oct-Dec;2(4):260-5.

32. de Jong RTH. Deliberate termination of life of newborns with spina bifida, a critical reappraisal. Childs Nerv Syst. 2008 Jan; 24(1):13-28. Discussion 29-56.

33. Almond D, Edlund L. Son-biased sex ratios in the 2000 United States census. Proc Natl Acad Sci USA. 2008 Apr 15;105(15):5681-2.

\section{Disability activism and non-invasive prenatal testing: A response to Breimer}

\section{ALEKSA OWEN, SATENDRA SINGH, KRISTI L KIRSCHNER}

\begin{abstract}
In his comment in IJME, Dr Breimer casts disability advocates as "special interest groups" and pits them against the abstracted concept of "women's autonomy." Against this, we assert that, far from only being a conflict of interest category, disability activism related to prenatal screening and testing is a robust part of bioethical debate and scholarship. Here, we disagree with Dr Breimer's characterisation of Noninvasive Prenatal Testing (NIPT) related disability activism as a threat to women's autonomy and respond to the underlying assumptions of his claims. We argue that disability need not be equated only with harm. Instead, we point out the dominant and intractable belief that disability is something to be avoided, which may lead to belief-based moral wrongs. This is the position from which disability activists make claims about the need to expand understandings of disability. Drawing on existing evidence, we find that prenatal testing does not automatically facilitate autonomy, and that NIPT may be even more of a challenge to autonomy than previous testing iterations. We suggest that NIPT should continue to be a phenomenon under close clinical scrutiny, and that ongoing debates and multiple claims-making can only add to our understanding of this phenomenon.
\end{abstract}

Keywords: non-invasive prenatal testing, disability rights, reproductive autonomy, harm principle, informed consent

Authors: Aleksa Owen (Aleksa.owen@gmail.com), Practice Fellow Association of University Centers on Disability, Washington, DC, USA; Satendra Singh (dr.satendra@gmail.com), Associate Professor, Department of Physiology; Health Humanities Group, University College of Medical Sciences, Delhi, India; Kristi L Kirschner (kkirschn@uic.edu), Clinical Professor, Departments of Medical Education, and Neurology and Rehabilitation, and Adjunct, Department of Disability and Human Development, College of Allied Health Sciences, University of Illinois, Chicago, USA.

To cite: Owen A, Singh S, Kirschner KL. Disability activism and non-invasive prenatal testing: A response to Breimer. Indian J Med Ethics. 2020 Oct-Dec; 5(4)NS: 290-3.DOI:10.20529/JME.2020.112.

Manuscript Editor:Vijayaprasad Gopichandran

(๑) Indian Journal of Medical Ethics 2020

\section{Introduction}

In his Comment published in this journal, Dr Breimer argued that disability advocates are threatening women's autonomy in the context of noninvasive prenatal testing (NIPT) (1).

Dr Breimer, here and elsewhere $(2,3)$ relegates positive views of life with disability to certain "religion and life views" (2), a viewpoint that can only be understood as a form of bias. We take issue with his assertion and rebut his conclusions here through two lines of argumentation. First, Dr Breimer's characterisation of disability advocates as impeding the technological progress toward healthier children rests, as far as we can tell, on a narrow conceptualisation of disability, specifically chromosomal anomaly, as harm. We discuss why this prevalent view of disability is problematic from the perspective of disability advocates, but also why it is the dominance of the belief itself that provides grounds for claimsmaking in favour of disability advocacy.

Second, Dr Breimer's conclusion that disability advocates are an obstacle to women's autonomy is wrong because it equates NIPT and other prenatal testing with autonomy, a relationship that may be more complicated than Dr. Breimer presents. We present evidence to back our position and conclude by suggesting that instead of assuming that more testing is an unquestionable social good, we can use NIPT and other technological medical advances to more deeply probe the social and ethical dimensions of clinical interactions and contexts.

Reproductive autonomy and disability rights need not be at odds; to pit them against each other is disingenuous and misses the core concerns of disability bioethics. Dr Breimer reduces disability advocates to special interest groups that are "anti-abortion." This is not true; many disability advocates who have critiqued prenatal testing have supported the right to abortion (4-9). We reject the notion that disability advocates are wholly trying to limit or block access to safe and affordable abortion, acknowledging that disability rights arguments have, at times, been co-opted by conservative anti-abortion positions as noted by Swaim (10). We suggest that instead of understanding disability advocacy groups as "special interest groups" infringing upon reproductive decision-making, disability bioethics arguments may re-frame 